\title{
A comparative analysis of Human Resource Development (HRD) in Public and Private Organizations inthe State of Jammu \& Kashmir
}

\author{
Towseef Ahmad Rather ${ }^{1}$, MohdYousf Rather ${ }^{2}$, Saba AhasanBhat ${ }^{1,}$ \\ Sheikh Imtiyaz $\mathrm{Ah}^{3}$ \\ ('Department of Social Sciences, India / IGNOU Delhi) \\ (2Department of English, RACE Anantnag, India/Kashmir University Srinagar) \\ ${ }^{3} \mathrm{CEO}$, India/ Comtech Group Srinagar)
}

\begin{abstract}
Thetitle of my paper is "Comparative Analysis of Human Resource Development in Public and Private Organizations in the State of Jammu \& Kashmir" which is based ontheresearchstudyentitled as "AStudyon Comparative Analysis of Human Resource Development in Public and PrivateOrganization in State Of Jammu And Kashmir". ThemainObjectiveofthepresentstudyisto takecognizanceof the developmentofHRDin State of Jammu and Kashmir. This has been done by establishing a comparative comparison between Private and Public Institutions in the State of Jammu \& Kashmir India, regarding the extent of implementation of Human Resources Management and Development (HRMD) practices. The data for the study was collected through a questionnaire comprising items mainly related to recruitment and placement, training and development, performance appraisal, compensation and benefits and employee relations. The study is a qualitative case analysis. It aims to see the similarities and or differences between a public and a private institution in the state Jammu \& Kashmir with respect to the implementation of latest practices in the development of human resource. In this paper some of the main findings of the study have been summarized and some important recommendations for the betterment of human resource have been presented.

Finally an HRMD modal has been presented for the development of human resource practices which is completely a novel creation of the research scholars of this project and is hypothetically recommended for better results.
\end{abstract}

Keywords: Human Resources Development HRD, Human Resources Management and Development HRMD

\section{Introduction}

Intellectual work is basic to any organization's performance, including the organizations, and the existence of them fully depends on knowledge, skills, competences and attitudes of the intellectual workers. Professionally trained, motivated and contributory personnel are the very crucial precondition for successful implementation of human resource mission and realisation of institutional functions, development and strategies. Goals of learning and growth of the organization's personnel describe how the composite of people, technologies and the organizational climate promotes the accomplishment of the strategy. At individual level, investing in human-resources promotes the growth of knowledge, skills and abilities, encouraging development and growth of the employee. On organizational level, it results in increasing productivity and efficiency. On social level, higher educated and developed individuals together with more efficient organizations provide growth of culture and economy, as well as improve the well-being of society.

Since in this regard Jammu and Kashmir is one of the backward areas and least attention has been paid towards the development of competent human resource. Although different governmental and private organisations are working in Jammu and Kashmir, yet the performance of these organisations is not coming up to the expectations of the administration as well as the public. A lot of work is still to be done in this respect with regard to the human resource development, particularly in backward areas like Kashmir.

In this respect my proposed research might be of some importance. And can pave the ways for further development of human resource with the implementation of latest technological skills ,development of positive attitude and the establishment of satisfactory work culture.it is an established fact that when the shortcomings of any organization are detected, appropriate remedial measures can be taken to overcome those out comings. My proposal is to locate the loop holes and point out the shortcomings in the human resource management of private and public organization in state and as a result some generalised special references shall be made with reference to whole Jammu and Kashmir. 


\section{Literature Review}

Expectedly the observations to be concluded on the completion of the project shell be of a great importance for the govt. Administration, private Management and the society as a whole. Organization's most valued assets - the people working there who individually and collectively contribute to the achievement of its objectives (Armstrong, 2006). Development of human resource management systems in public sector organizations can be analysed by using several models (Ban, 2005). In the strategic human resource management model managers of personnel management departments or services work as full-fledged members of the organization's management team, merging the strategy of personnel and human resource management with the mission, goals of the organization and the institution's working strategy, therefore making human resource management a part of the organization's strategic planning process. The term "human resource strategy" usually applies to a set of coordinated decisions and actions which formulates and directs human resource management (recruitment, positioning, utilizing, developing and rewarding) in the context of achieving the organization's goals. In this process the understanding of human capital as a value of the organization becomes important. Human capital is characterized by the knowledge and skills of employees that can be considered as the most significant resource, particularly in intellectual organizations. Intellectual work is crucial in the performance of a public sector organization as an intellectual organization, and its existence relies greatly on the intellectual abilities of personnel members. Different approaches in the achievement of strategic management of human resources are reflected in the human resource management's priority of either "humans" or "resource". "Hard" human resource management emphasizes the aspect of "resource" and sees a firm integration of human resource politics, systems and activities in the organization's strategy as crucial (Hendry \& Pettigrew, 1990). From this point of view a person is perceived as a passive resource that holds the necessary skills and is available for an appropriate price, instead of being perceived as a source of creative energy; personnel recruitment, assessment, development and rewarding is done for the purpose of establishing the organization's performance, and the actions towards human resource development are subordinated to strategic goals of the whole organization(Gubbins\&Garavan, 2005). "Soft" human

Resource management is based on the epistemology of human relations and emphasizes the importance of communication, team work and employing individual talents (Poole \& Mansfield, 1994; Legge, 2005). P.F.Drucker (2007) draws attention to six factors that are vital to productivity of intellectual workers, but as the demands of the intellectual worker's organization and performance environment vary, these factors may have a different influence and prospects of achievement. Considering that the decisions of PA are being made and services are provided according to restrictions and priorities formulated by the politically administrative system, the most important factors that influence labour productivity of public administration's intellectual workers are the employee's understanding of the core of the task and the goals to be achieved; a chance to take part in and contribute intellectually to the management processes of both their work and the whole organization; a chance to continually learn and develop; the selection of qualitative work assessment methods; work conditions and the organization's inner culture that is both motivating and promotes a creative work atmosphere. During the creation of the organization's strategy attention is paid to the production of a human resource development program (recruitment, learning and career development) - it forms the human capital of organization. Most human resource development programs try to satisfy the needs of all workers, and therefore employees whose work is strategically significant for the organization do not receive enough investment. In the strategic job family model an organization focuses human resource development programs on several critical jobs that have a significant impact on the accomplishment of strategy, therefore ensuring a rapid process of actions and a rational resource spending. However, this approach also describes up to $90 \%$ of workers as "non-strategic", and the organization might end up ignoring their reasonable need for development. The strategic value model (Kaplan \& Norton, 2004) holds a premise that the job of every worker is strategic - a strategy contains values and priorities which can be included in the goals and actions of every worker.

Personnel assessment is closely related to further development of employees. Assessing the performance of a worker in the previous period can help identify areas which need improvement, while the assessment of potential allows identifying the competences which may be crucial in successful development of the worker's further career. The study that was carried out in several European countries (Mathews et al., 2001) shows that the worker's education needs are usually influenced by decisions of the supreme management and direct managers, thus pushing most other methods aside. That might lead to a conclusion that learning might be a process imposed by management, while it can also be interpreted as the assurance of strict management in matters of education quality. A variety of assessment methods for education needs can reduce the influence of subjective methods and the management's control processes. Another important aspect of assuring a wholesome effective civil service management, including the development of human resources, is the approach of either centralization or decentralization of matters of personnel management and development in the Public Administration (Pollitt \&Bouckaert, 2004). Traditionally the Public Administration systems tend to have a centralized personnel management. Organizations (institutions and agencies) have a relatively low chance to 
choose their personnel management system freely and develop it; they are obliged to function according to the current civil service law. Matters of administration of the civil service, organising tests for recruiting and promoting, creation of a work pay policy and other functions are the responsibility of centralized structures (e.g. The State Civil Service Administration). It also ensures coordinated actions of organizations, objectivity and precision as well as high professionalism, but it also creates flaws such as bureaucracy, delays and the inability to adapt to changes in external environment in time.

Human resources development is a continuing process comprising three interdependent components:

- Investment in human resources to enhance productive capabilities.

- Utilization of those human resources to produce increased output.

- Participation of the human beings who have improved resources (better education, better skills levels etc.) In the consumption of that increased output through a better quality of life (See fig 1.1)

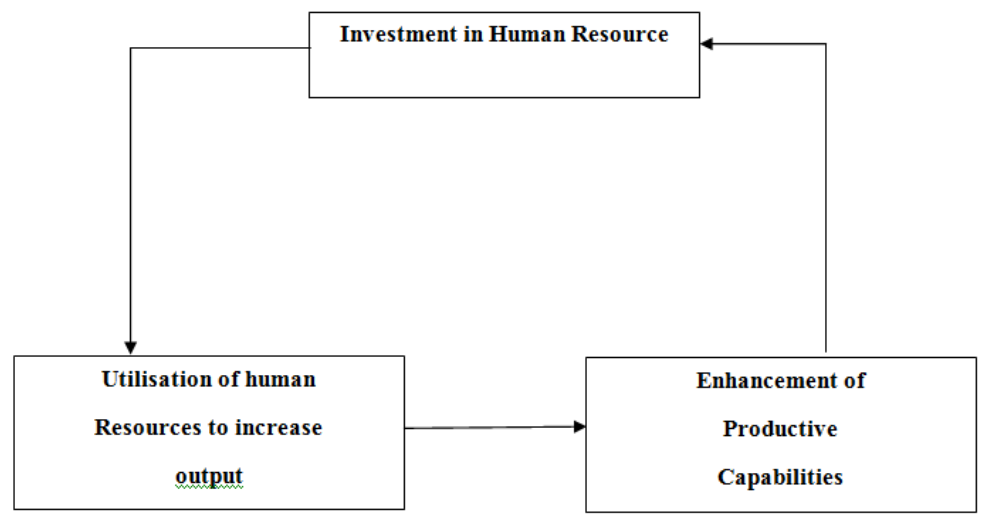

Fig 1.1

Sustainable human resources development must involve all three components, as seen in the diagram above. At a national level, investment in human resources must be turned into effective utilization of those human resources if national output is to be increased on a sustainable basis.

At an individual level, investment in human resources improves earning capabilities. Therefore individuals and families have more money to do many things including pay for their own further skills development. There is a very strong link between investing inhuman resources development and improvements in the quality of life. Improvements in nutrition, health and education are key elements of an improved quality of life and must be considered important investments in human resources, particularly in Investment in Human Resources Utilization of human resources to increase output Enhancement of productive capabilities. Developing countries, Human beings cannot be developed if they do not have enough food, are in poor health or cannot read or write. For developing countries, it is extremely important that all members of the society have access to human resource development activities, especially the poor, women and populations in rural areas.

Participation and choice are key elements in this view of human resource development. The financial reward obtained from participation in production activity is the main way that individuals are able to participate in the quality-of-life benefits that are created by development. Increased job satisfaction and a sense of personal worth arising from increased productivity are also very important contributions to quality of life. The enhanced capabilities created by development enlarge the choices made available to both individuals and nations.

Historically, HRD has referred to developing human resources in order to increase economic productivity and therefore a nation's wealth, which is, very closely linked with economic outputs. However, within current definitions and discussions, especially in the context of developing countries, there is more emphasis on the human aspects of HRD. So, in the development context the meaning of the term's human resources development and human development are very much interconnected.

\subsection{RecruitmentandPlacement}

\section{Basic points for successful Human Resource Development}

AnimportantfunctionofHRMistoensurethat the organizationhasanadequatesupplyof human resources to allevels andinallpositions atthe righttimeandin theright placetoman thejobs thathavebeenproperlyidentifiedanddescribed.

Kleiman(2000)definedhuman resource planning as an HRM practice that helps managers anticipate andmeetchangingneedsrelatedtothe acquisition, deployment andutilization ofits employees. Noeetal.(2004)statedthatthefirst stepinhumanresource planning ispersonnel forecasting.Forecastingattempts todetermine the supplyof,anddemand for varioustypesofhuman resources topredactoraswithintheorganization wheretherewillbelabourshortagesandsurpluses. 
Hill(2000)mentioned thathighereducation institutionshavebegunadopting corporatestyle human resourcemanagementpractices such as careful recruitmentand selectionof staff, extensive use of systems and communication, teamworking, individualresponsibility for trainingandlearning,moreparticipation in decisionmaking and use of performance

Itwasalsopointed outthatbecause of datainformation andtechnology,theneedto updatetheworkers toadjusttoaveryfast changingenvironmentis vitalin order for the organization tocompete,survive, andexcel. Moreover,gapsinknowledge, skillsandattitudes canbefilledinevenwiththeminute'sreference bookinanofficeoffactorybookshelf orbya professional helpingintraining,patching, and counselling programs.

They alsoexpressed theneedforneeds assessment prior tothe conductof aprogram. Needsassessment consistofanorganization analysis,personanalysis, andtaskanalysis?

\subsection{PerformanceAppraisal}

Kleiman(2000)definedperformance appraisal as theassessment of employees'job performance levels.Aneffective performance appraisal system can create competitive appraisal andperformancemanagement techniques

\subsection{TrainingandDevelopment}

AccordingtoNoeetal.(2004),inthe economics ofwork, theforwardlooking management isonewhichprovidesopportunities fordevelopmenttohumancapital.Employeescan bebestpartners inanyenterprise ifthey are maximally developedandwhentheyreachtheir optimumpotential.

According tom them,jobapplicantswhen hired,consciouslyorunconsciously,thinkofhow theycangrowingandonthejobandorganization. It isnot enoughthat whateverknowledgeand skillsemployees bringtotheirorganizationwhen newly hired are fullyutilized. They should acquireadditional capabilitiesformore responsibilities intheircurrentandfuture positions.Advantagebyimprovingemployeejob performance intwoways:bydirectingemployee behaviourtowardorganizational goalsandby monitoring thatbehaviourtoensurethatgoalsare met.

Agoodperformance appraisal system reinforces an organization's strategicbusiness plan by focusing attention on employee'sprogress towardmeeting theirportion ofplan.In effect, appraisalsystem lets employees know whatisexpected ofthemindthuschannelstheir behaviour'sto properdirections.

Thestudy ofShepherdetal(2009) revealed thatregularandfrequent performanceevaluations arearoutinepart oflifeformarketing faculty, whatevertheirinstitutionalaffiliations.

\subsection{CompensationandBenefits}

Jobevaluationisaimedatdetermining relative worthofajob.Itcomparesjobstoanotherbased ontheircontentwhichisusually definedin termsofcompensable factorslikeskills, efforts, responsibilitiesandworkingconditions.

AccordingtoNoeetal.(2004), incentive payispaidtoindividualperformance, profits andothermeasures ofsuccess.Organizations selectformsofincentivepaytoenergize, director controlemployees' behaviour.Itisinfluential becausetheamount paidislinkedtopredefined behaviour'soroutcomes.

Dessler(2000)mentionedthatincentives are usuallypaid to specific employees whoseworkisabovestandard.Employeebenefits, on theotherhand,areavailable toallemployees basedontheirmembership intheorganization. Therearefour typesofbenefit plans: pay supplements, insurance, retirement benefitsand services.

\subsection{EmployeeRelations}

Employee relationsinvolvethebody of workconcernedwithmaintaining employeremployeerelationships thatcontributeto satisfactory productivity,motivation,andmorale. Essentially, employee relations are concerned with preventingandresolvingproblemsinvolving individualswhich arise outoforaffectwork situations.

Conflicts intheinstitutionsneedtobe addressedimmediately. According toJocano(2001), the mosteffectivemethodofresolving workers'grievancesagainstmanagement and management's grievancesagainstworkers isthe informaldialoguebetweentheaggrievedworker orhisrepresentatives andmanagement representatives.

\section{Conclusion}

The conclusion of the study indicated; a) Leadership performance at Private sector is higher than Public sector organization. b) The leadership roles in private sector bank were significantly higher on all the ten competencies as compared to public sector bank. Results are evident in this regard. c) The leadership roles in private sector hospital were significantly higher on strategy, communication, relationships, delegation and 
confidence as compared to the public sector hospital. d) The leadership roles in public sector airline were significantly higher on strategy, knowledge, learning, influence, relationship, integrity and confidence as compared to the private sector airline. Findings further report that 360-degree assessment tool provides more accurate and justified evaluation of an individual's competencies to judge his performance as a leader. Further it has been concluded that leadership development is an essential element to improve the organizational infrastructure. Training of public and private sector professionals must incorporate leadership skills and knowledge to augment the overall competency of the workforce. Despite all concerns, we believe that the enhancement of Leadership Role and Competency is a unique and groundbreaking contribution that can be used by both public and private sector organizations. Developing qualified and able public and private sector leaders is a critical step in building theinfrastructure needed to address organizational challenges in both the sectors. On behalf of this study, it was observed that proper HR practices are not followed by the most of organisations irrespective of their public or private status. It was found that private sector banks are having, to some extent, satisfactory leadership performance as compared to public sector organisations. As for the employee-employer relationship proper HRD mechanism is not followed. It is inspirational that some or all of the HRD mechanisms are being used by all the co-operative units. In case of compensation and benefits, the relationship between the employee and the employer are lacking mutual understanding, trust, confidence and loyalty which affect the working of employs badly.

\section{Recommendations}

On behalf of this study; it was observed that proper HR practices are not followed by the most of organizations irrespective of their public or private status. It was found that private sector banks are having, to some extent, satisfactory leadership performance as compared to public sector organizations. As for the employee-employer relationship proper HRD mechanism is not followed. It is inspirational that some or all of the HRD mechanisms are being used by all the co-operative units. In case of compensation and benefits, the relationship between the employee and the employer are lacking mutual understanding, trust, confidence and loyalty which affect the working of employs badly.
* ToimprovethequalityofHRM, leaders
must changetheparadigmshiftfromManagertoLeadershipis essentialinallthepublicandprivatesectororganizations. There is coordination needed in every part of the HR departments by which the mission of an organization should be got accurately and smoothly. Withinpublicsector,the leadershipstyleisstillHegemonic/AutocratandhasnotenteredtheareaofInternational phenomenonofleadershiptilltodate. Thereisneedtoswitchoverparticipativeand democratic style of leadership.

* Organizationsshouldensurethatcommunicationprocessshouldflowinalldirections, upward,downward,inparalleljustasofconceptof360degreeFeedbacktoreachout desired results from the employees. By which the role and responsibilities of leader is becoming complex.

* Leadershipneedsassessmentforimprovement. Forimprovementofbehaviourskill andtraits, training, development ofpersonalitytoperformbetterleadershiproles, frequentuseof 360 ofeedback assessment should be made in organizations from all sectors upward, downward, and parallel also to get feedback from down lines of organization .

* In?Developingpaysystemsandotherincentives, thepublicsectorisnotusuallyable to compete with the salaries offered by private employers ,like HDFC Bank and Khyber hospital especially those of highly- educatedpersonnel, doctorsandmanagers. However,payincreasesmaybenecessarytoprevent an outflow of highlyqualified personnel in private organizations.

* Regularmonitoringandevaluationofstrategicactionsisacrucialpartoftheprocess andisatoolforcontinuingdevelopmentandimprovement.Thistoolshouldjudicially be utilized in every organization.

* PublicandPrivatesectorBank'sLeadersinIndia and state of Jammu and Kashmir needtocompeteandexcelacross tencommoncompetencies/roleswhichwillprovidesubsequentoutcomeofbetter human service:

* ThePublicandPrivatesectoreducational institutes needtobetrainedfor improvement of their leadership competencies which will result into performance of educational activities in better way. They need to make good and cheap fee structure in the educational institutes.

* ThePublicandPrivatesectorHospitalin Jammu and Kashmir must beabletoengagein newthinkingandhelpexecutivemanagementtodevelopnewdirectionstosuccessfully 
competeinanincreasinglychallengingenvironment. Theyneedtoexplorestrategies tomeasureprogressthroughasetof"vitalsigns"andcontinuallyredirecttheorganization torespondtochangeandopportunity.HospitalCEOsandtheirboardsmustbuildand sustainvibrant, trust-basedrelationshipsinordertosuccessfullynavigatetheopportunities andchallengesintoday'scomplexandfast-pacedhealthcareworld. Trustisaresult ofhighintegrity,clearandconsistentcommunication,well-definedrolesand responsibilities, andwell-articulatedperformanceexpectationsandaccountabilities. Hencetheyneedtoexplorethedynamicsofbuildingaboard/CEOrelationshipwhere thebestskillsandresourcesofeachareusedtodevelopsynergisticleadershipthat confidence and drives high performance.

inspires

\section{SuggestedNewHRDModel:}

On thebasisof thefindingsof thepresentresearch,thefollowing newHRDmodelissuggestedapplicabletoalltypesofOrganizations. Thismodelcontainsthefollowing10elements.

1) HRDpolicies\&philosophy for the basic development of organization by which organizations attain there mission.

2) IntroductionofHRDmechanisms very clearly between employees and employer.

3) CreationofHRDclimate with a basic culture in the organization.

4) NeedbasedTrainingfacilitiesoffertotheemployees to gain objectives clearly which shall be start with the induction training programme?

5) Introduction of suitable A p praisal s y s te m characterized b H R Orienteer to gain better outputs from the employees.

6) Creating a "Developmental Leadership Styles" among themanagerialemployees by which subordinates remain under organizational rules and regulations.

7) Inculcatingcounsellingattitudeinthemanagerialemployees.

8) Assignment of HRD tasks to the HRD department or anindependentHRDmanager shall work for it.

9) Periodicalreview\&revision of theHRDactivities shall be taken by which follow remain smooth

10) Enhancementofthesystemonregularbasis.

Thesuccess ofthe

modelwilldependuponthequality,sincerity, honesty,rigorousness,perseveranceandpatienceof thepeople implementingthesame. Thepositiveenvironmentin andoutsidethe organizationis apre-requisiteforthesame. Allmodels ultimatelyareas good or bad, as the peopleimplementingit.

Hence

becreatedandmaintainedforsustainablegrowthofthe

ThenewHRDmodelwillbehelpfulinthecompetitive

environment.HoweverHRDbeingasmoothsocialscienceitssuccess organizationtoorganization, andsituationtosituationandtimetotime. conductiveHRDclimateneedsto organization.

\section{Ess Tee's New HRDModel}

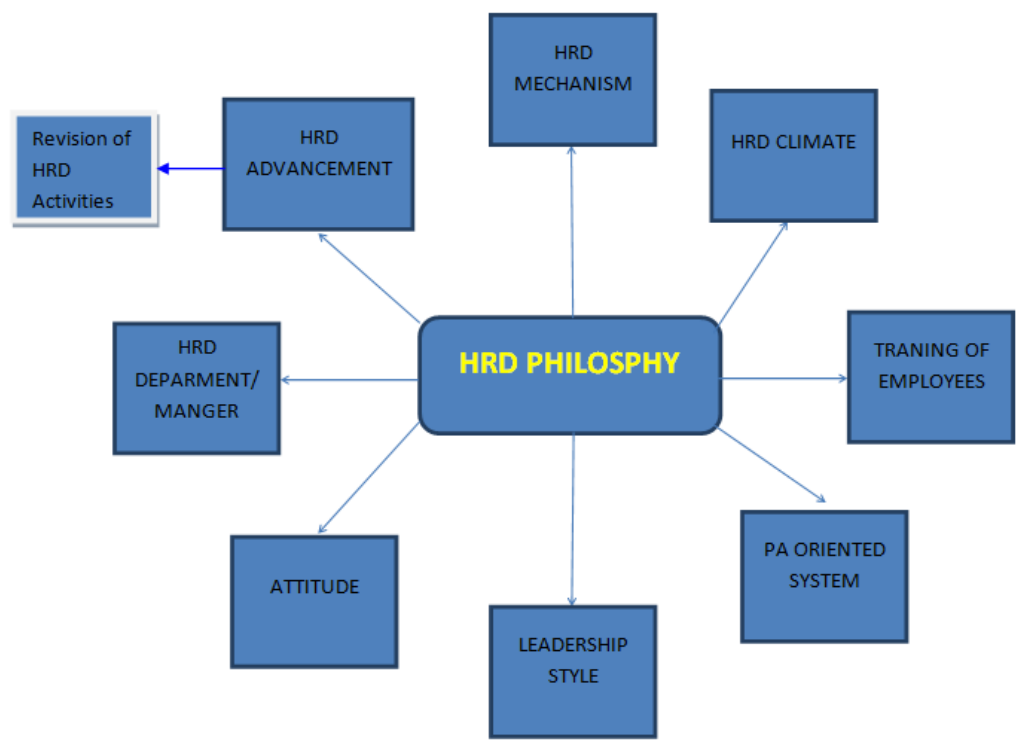




\section{Acknowledgement}

I sincerely enter my gratitude to Prof. Mohd. Yousf Rather,Mr.Mehrajud Din, Miss KhalidaAkhter and Mrs.RifatHameedfor his dedicated supervision and guidance, which has played the major role in the completion of this Research Paper

\section{Towseef Ahmad Rather \\ References}

\section{Books}

[1] Fombrun, C.J., Tichy, M.M., Devanna M. A. (1999). Strategic Human Resource Management.New York: JohnWiley.

[2] Ali, Shum Sun Nisa, (1977), Eminent Administrative Thinkers, Associate Publishing House, New Dehli

[3] Battacharaya, Mohit, (1981), Public Adminstration: Structure, Process And Behaviour, The world press pvtltd Kolkata.

[4] Prasad D. Ravindra, V.S Prasad and P.Satyanarayan,(2004), Adminstrative Thinkers(ED).Sterling Publishers, New Dehli.

[5] Armstrong, M. (2006). Strategic Human Resource Management: A Guide to Action, 3rd Edition. London: KoganPage Publishers.

[6] Bach, S. (2005). Managing human resources: personnel managementin transition, 4th Edition, Wiley-Blackwell.

[7] S. E. Condrey (Ed.) Handbook of HumanResources Management inGovernment, 2nd Edition, Jossey-Bass, 17-36

[8] Drucker, P.F. (2007). Management Challenges for the 21 st Century. Amsterdam: Elsevier Science \& Technology.

[9] Fombrun, C.J., Tichy, M.M., Devanna M. A. (1999). Strategic Human Resource Management.New York: JohnWiley. 